\title{
NON-STATIONARY ELECTROCHEMICAL RESPONSE OF POLYCRYSTALLINE CADMIUM IN SODIUM HYDROXIDE SOLUTIONS
}

\author{
S. B. Saidman, J. R. Vilche and A. J. ARvin
}

Instituto de lnvestigaciones Fisicoquimicas Teóricas y Aplicadas (INIFTA), Facultad de Ciencias Exactas, Iniversidad Nacional de La Plata, Casilla de Correo 16, Sucursal 4, 1900 La Plata, Argentina

(Received 17 July 1986)

\begin{abstract}
The anodization of cadmium in $\mathrm{NaOH}$ solutions produces a hydrous cadmium hydroxidecadmium oxide layer and soluble cadmium specics in solution. These processes are investigated through conventional voltammetry, potentiostatic, rotating ring disc electrode and complex voltammetric techniques by using $\mathrm{NaOH}$ solutions in the $0.01-1 \mathrm{M}$ range at $25^{\circ} \mathrm{C}$. The threshold potential of the anodic reaction is very close to the reversible potential of the $\mathrm{Cd} / \mathrm{Cd}(\mathrm{OH})_{2}$ electrode. The overall anodic and cathodic reactions can be interpreted through a complex reaction model comprising a number of parallel reactions following the initial formation of $\mathrm{CdOH}_{\mathrm{ad}}$ species at the electrode surface level. The relative contribution of each parallel reaction is determined by the concentration of $\mathrm{OH}^{-}$ion at the interface. The reaction model implies a composite structure of layers starting from $\mathrm{CdOH}_{\mathrm{ad}}$ at the electrode surface, and subsequent layers with an incitase in the water content on approaching the outmost oxide layer. The water content of anodic layer should increase according to the pH and layer thickness and docrease on increasing the applied potential. Under certain conditions the electrochemical reactions become ohmic resistance controlled. This fact presumably involves the formation of aged species and the onset of passivity.
\end{abstract}

\section{INTRODUCTION}

The electrochemical studics of cadmium are closely related to its application in alkaline batteries, the electrodcposition of cadmium is particularly important in electronics, and the semiconductor properties of some cadmium chalcogenides. Reviews of the literature on cadmium electrodes[1-5] show that attention has been preferentially paid to the thermodynamics: and kinetics of the clectrochemical reactions in concentrated base solutions, particularly with porous electrodes, in relation to the performance of these electrodes in $\mathrm{Ni}-\mathrm{Cd}$ battery cells[6-10]. Despite the relatively abundant information available on the behaviour of plain cadmium in base solutions[11-26], there are still relevant questions requiring further research related to the composition and structure of anodically formed films, the mechanism of the corresponding reactions, and the participation of soluble cadmium species in those reactions.

The present paper refers to the non-stationary response of polycrystalline cadmium electrodes in $\mathrm{NaOH}$ solutions to determine the influence of potential and time on the electroreduction characteristics of the hydrous cadmium hydroxide layer and cadmium species in solution, in relation to certain anomalous voltammetric responses of cadmium in base solutions.

\section{EXPERIMENTAL}

The experimental setup was described in previous publications [27, 28]. "Spexpure" cadmium (Johnson Matthey Chemicals Ltd) in the form of rotating discs $\left(0.20 \mathrm{~cm}^{2}\right.$ apparent area) axially mounted in a PTFE holder were used as working electrodes. The counterelectrode was a large area Pt sheet. Potentials were measured against a saturated calomel reference electrode properiy shielded and connected through a Luggin-Haber capillary tip. Potentials in the text are referred to the nhe scale. Each cadmium electrode was polished sucxessively with 400 and 600 grade emery paper, $1 \mu$ and $0.3 \mu$ grits aluminia-acetone suspension, thoroughly rinsed with thrice distilled water, and finally, held for $5 \mathrm{~min}$ in the hydrogen evolution potential region to attain a reproducibie electroreducted initial metal surface. Runs were made in $x M$ $\mathrm{NaOH}$ solution, $1 \geqslant x \geqslant 0.01$, prepared from a.r. Merck $\mathrm{NaOH}$ and thrice distilled water, at $25^{\circ} \mathrm{C}$, under purified nitrogen. The current/potential characteristics were recorded by applying to the electrode cither still $(\omega=0 \mathrm{rpm})$ or under rotation $(0 \mathrm{rpm} \leqslant \omega$ $\leqslant 2600 \mathrm{rpm}$ ) the following potential programs: (i) conventional triangular potential sweeps either single (STPS) or repetitive (RTPS) between preset cathodic $\left(-1.76 \mathrm{~V} \leqslant E_{s, t} \leqslant-0.76 \mathrm{~V}\right)$ and anodic $(-0.76 \mathrm{~V}$ $\left.\leqslant E_{s, a} \leqslant 0.24 \mathrm{~V}\right)$ switching potentials at different potential sweep rates $\left(0.001 \mathrm{Vs}^{-1}<v<20 \mathrm{~V} \mathrm{~s}^{-1}\right)$; (ii) constant potential steps; (iii) combined either STPS or RTPS with different potential steps; (iv) combined RTPS with TPS; and (v) triangularly modulated triangular potential sweeps (TMTPS) with a guide ramp at $v_{g}=0.5 \mathrm{Vs}^{-1}$, and a modulating RTPS of different amplitude $\left(0.1 \mathrm{~V}<A_{m}<0.2 \mathrm{~V}\right)$ and potential sweep rate $\left(20 \mathrm{Vs}^{-1} \leqslant v_{m} \leqslant 60 \mathrm{Vs}^{-1}\right)$. To detect the formation of soluble cadmium species the rotating ring-disc electrode (rrde) technique was also employed. For this purpose a cadmium disc-cadmium ring electrode was made, its collection efficiency being 0.27 . 


\section{RESULTS}

\section{Conventional voltammetric data}

The voltammetric response of cadmium depends on the stirring conditions, the number of potential scans, the potential sweep rate and the switching potential values. The influence of these variables becomes more remarkable on increasing the concentration of $\mathrm{NaOH}$ from $0.01 \mathrm{M}$ to $1 \mathrm{M}$.

The voltammogram run with a cadmium electrode in $0.01 \mathrm{M} \mathrm{NaOH}$ at $v=0.1 \mathrm{Vs}^{-1}$, between $E_{s, c}=$ $-1.36 \mathrm{~V}$ and $E_{s, a}=0.24 \mathrm{~V}$ from $5 \mathrm{~min}$ to $30 \mathrm{~min}$ potential cycling for a still electrode (Fig 1a) changes little, in contrast to the remarkable change noticed for a rotating electrode (Fig. 1b). For the latter the anodic charge in the first voltammetric scans and the cathodic current at negative potential are relatively larger than those obtained for a still electrode (Fig. la). However, after a prolonged potential cycling a common voltammogram is approached, independently of stirring. At any rate, in the positive potential scan the anodic current initiates at a potential very close to the $\mathrm{Cd} / \mathrm{Cd}(\mathrm{OH})_{2}$ reversible electrode potential[29], and at more positive potentials at least two peaks (I and II) are recorded. The returning scan presents a complex peak (III) and a net cathodic current at potentials nore negative than $-1.1 \mathrm{~V}$.

On the other hand, the voltammogram of cadmium in $1 \mathrm{M} \mathrm{NaOH}$ run at $0.1 \mathrm{Vs}^{-1}$ between $c a-1.46 \mathrm{~V}$ and $0.04 \mathrm{~V}$ shows during cycling a new cathodic peak (IV) and a progressive increase in both the voltammetric charge and the cathodic current contribution at negative potentials (Fig. 2). The increase in charge for peaks I and IV becomes more remarkable than that for peaks II and III, and it occurs without any shift in the corresponding peak potentials. These changes are less noticeable in $1 \mathrm{M} \mathrm{NaOH}$ under $\mathrm{CdSO}_{4}$ saturation. Further RTPS measurements at high $v\left(20 \mathrm{Vs}^{-1}\right)$

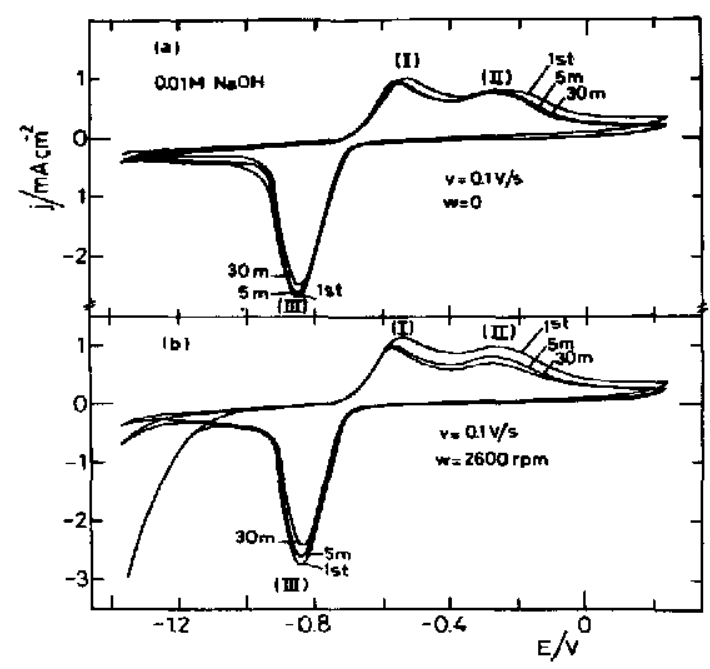

Fig. 1. RTPS voltammograms, $v=0.1 \mathrm{Vs}^{-1}, E_{s, c}=$ $-1.36 \mathrm{~V}, E_{\mathrm{s}, a}=0.24 \mathrm{~V}, 0.01 \mathrm{M} \mathrm{NaOH}$. The first cycle and profiles after $5 \mathrm{~min}$ and $30 \mathrm{~min}$ R TPS are indicated. (a) $\omega=0$; (b) $\omega=2600 \mathrm{rpm}$.

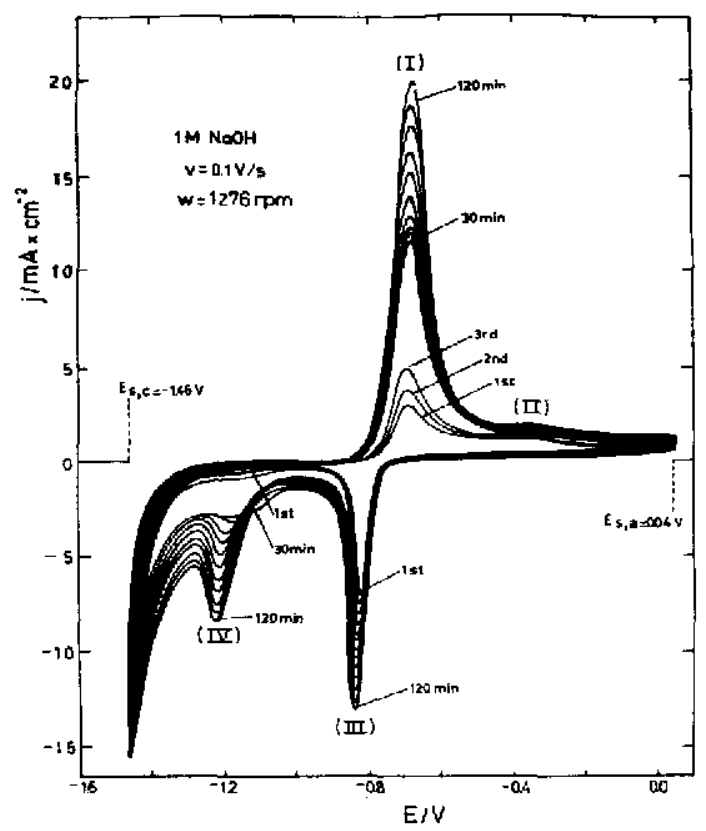

Fig. 2. RTPS voltammograms, $v=0.1 \mathrm{Vs}^{-1}, \quad E_{s . c}=$ $-1.46 \mathrm{~V}, E_{\text {s.a }}=0.04 \mathrm{~V}, 1 \mathrm{M} \mathrm{NaOH}, \omega=1276 \mathrm{rpm}$.

reveal a remarkable reversibility of the initial stages of the electrooxidation process (Fig. 3).

For a still cadmium electrode the stabilized voltammograms resulting for the different solutions at $0.1 \mathrm{Vs}^{-1}$ between $c a-1.46 \mathrm{~V}$ and $0.24 \mathrm{~V}$ (Fig. 4) show, in principle, qualitatively the same features already described, but the overall anodic to cathodic voltammetric charge ratio $\left(Q_{a} / Q_{\varsigma}\right)$ approaches 1 as the $\mathrm{NaOH}$ concentration decreases. In these cases the increase in charge of peak $I$ is associated with the increase in the cathodic current extending from $-1.0 \mathrm{~V}$ downwards. This effect is presumably related to the simultaneous formation of soluble ionic cadmium species and the anodic layer in the potential range of peak I. For any $\mathrm{NaOH}$ concentration, the voltammetric profiles plotted as $j v^{-1}$ vs $E$ diagrams become extremely dependent on $v . \ln 0.01 \mathrm{M} \mathrm{NaOH}$ at very low $v$ a complementary pair of very sharp peaks appears in the potential range of peaks I and III (Fig. 5). The threshold potentials of both sharp peaks lie very close to the equilibrium potential of the $\mathrm{Cd} / \mathrm{Cd}(\mathrm{OH})_{2}$ electrode in $0.01 \mathrm{M} \mathrm{NaOH}(E /$ nhe $=$ $-0.706 \mathrm{~V}$ ). In this case, the heights of peaks I and II decrease with increasing $v$, independently of stirring. Likewise, peak III is made of different contributions which in turn depend on both $v$ and $\omega$. For constant $E_{s, c}$ and $E_{s, n}$ values, $Q_{a}$ becomes independent of $\omega$, but it decreases as $v$ increases, whereas $Q_{c}$ for peak III depends on both $\omega$ and $v$. Furthermore, for a constant $\omega$ (Fig. 5b), as $v$ increases $Q_{c}$ decreases, peak III becomes broader and its peak potential ( $E_{p, \text { III }}$ ) results progressively more negative. On the other hand, for a constant $v$, stirring comparatively decreases the current contribution of peak III with respect to the cathodic 


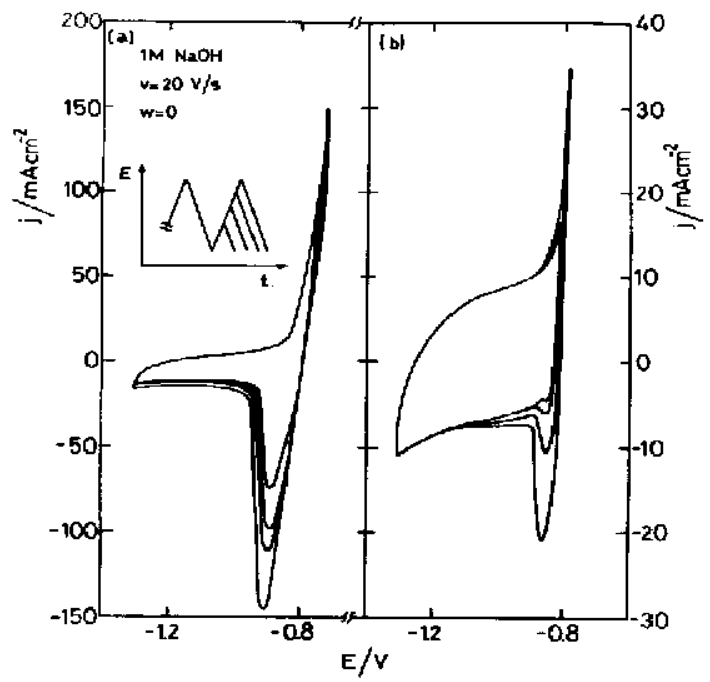

Fig. 3. Voltammograms involving a gradual decrease in $\boldsymbol{E}_{\mathbf{s}}$; $v=20 \mathrm{Vs}^{-1}, 1 \mathrm{M} \mathrm{NaOH}, \omega=0$. Runs include a RTPS hetween $E_{s . c}=-1.36 \mathrm{~V}$ and $E_{s, a}=-0.36 \mathrm{~V}$ to attain the stabilized voltammogram before changing $E_{s, a}$.

current for $E<-0.8 \mathrm{~V}$, and it increases the contribution of the humps at both sides of peak III. From these results one infers that the overall reaction involves one set of proccsses depending simultaneously on $v$ and $\omega$, and another one depending only on $v$ and practically independent of $\omega$.

Further details of the entire process can be discovered by setting $E_{x, a}$ in the potential range of peak 1 . The corresponding $j v^{-1}$ vs $E$ plots for a still cadmium electrode in $0.01 \mathrm{M} \mathrm{NaOH}$ (Fig. 6a) show that as $v$ decreases, the height of peak I increases, $E_{p, I}$ becomes more positive, and peak III splits into components III $^{\prime}$ and III". In addition, the component $^{\prime \prime} I^{\prime}$ is enhanced at low $v$. On the other hand, under rotation (Fig $6 \mathrm{~b}$ ) component III' turns into a broad peak, peak III" is

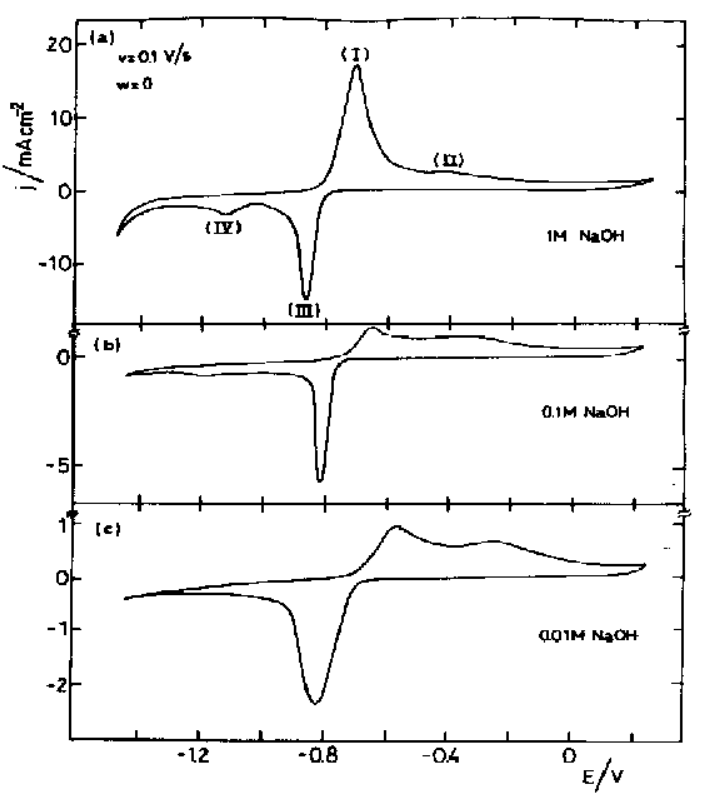

Fig. 4. Influence of the concentration of $\mathrm{NaOH}$ solution on the stabilized voltammograms, $v=0.1 \mathrm{Vs}^{-1}, E_{s, \varepsilon}=$ $-1.46 \mathrm{~V}, E_{x, a}=0.24 \mathrm{~V}, \omega=0$. (a) $1 \mathrm{M} \mathrm{NaOH}$; (b) $0.1 \mathrm{M}$ $\mathrm{NaOH}$; (c) $0.01 \mathrm{M} \mathrm{NaOH}$.

enhanced and the anodic charge results comparatively smaller than that resulting for still electrodes (Fig- 6a). Otherwise, at high $v$ the voltammogram becomes practically independent of $\omega$. The charge of peak I resulting up to $E_{p, \mathrm{I}}$ for runs starting from $E_{s, c}=$ $-1.36 \mathrm{~V}$ fits a linear $Q_{p, 1}$ ws $v^{-1}$ relationship, whose slope tends to zero as the concentration of $\mathrm{NaOH}$ decreases from $1 \mathrm{M}$ to $0.01 \mathrm{M}$ (Fig. 7). Under the same experimental conditions the $\log j_{p, I} v s \log v$ plot approaches a linear relationship with a slope close to 0.5 for any $\mathrm{NaOH}$ concentration (Fig. 8a) and the $E_{p, I}$ $v s \log v$ plots exhibit reasonable linear relations with an

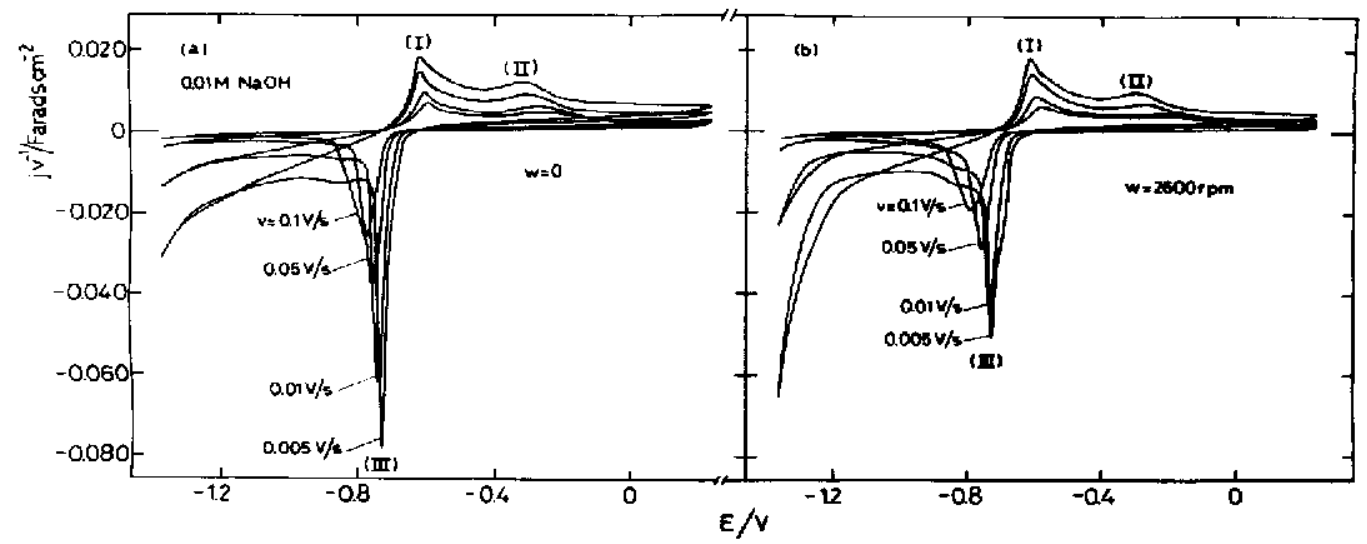

Fig. 5. $j v^{-1} v s E$ plots from RTPS voltammograms recorded at different $v . E_{x, c}=-1.36 \mathrm{~V}, E_{x, a}=0.24 \mathrm{~V}$, $0.01 \mathrm{M} \mathrm{NaOH}$. (a) $\omega=0$; (b) $\omega=2600 \mathrm{rpm}$. 


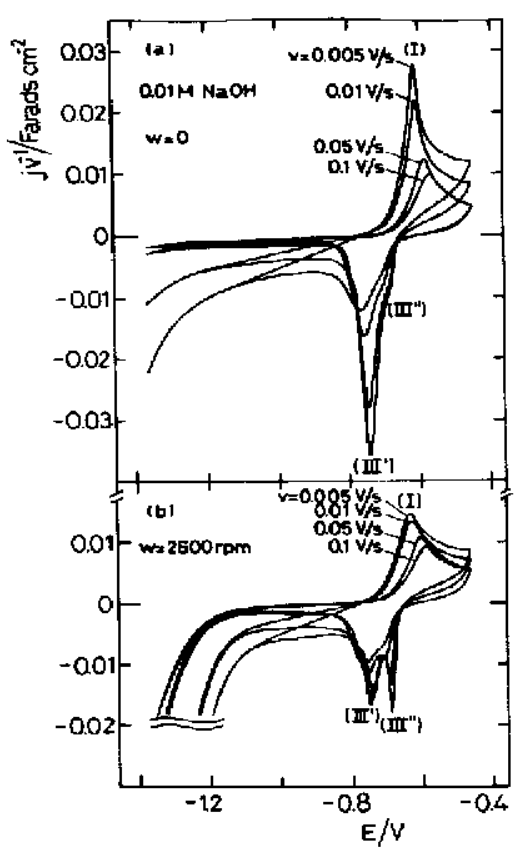

Fig. 6. $j v^{-1}$ us $E$ plots from RTPSvoltammograms recorded at different $v . E_{s, c}=-1.36 \mathrm{~V}, E_{s, a}=-0.46 \mathrm{~V}, 0.01 \mathrm{M}$ NaOH. (a) $\omega=0$; (b) $\omega=2600 \mathrm{rpm}$.

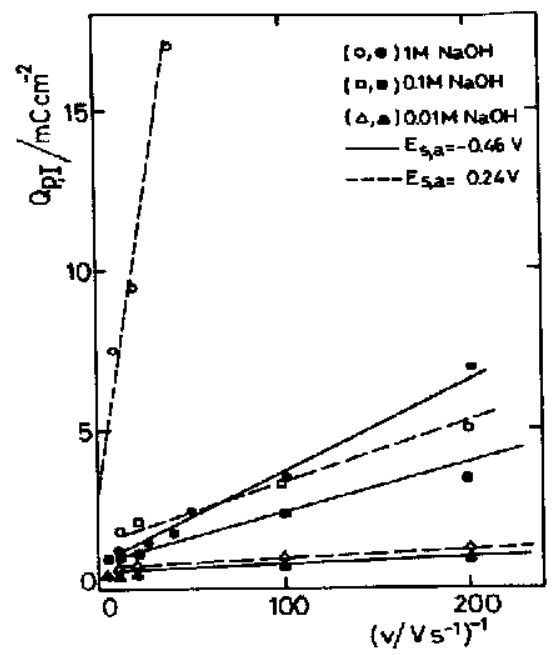

Fig. 7. Dependence of $\left(Q_{p .1}\right)$ on $v^{-1}$ from stabilized voltammograms. $\omega=0, E_{s, c}=-1.36 \mathrm{~V}, E_{s, a}$ either $0.24 \mathrm{~V}$ (Fig. 5a) or $-0.46 \mathrm{~V}$ (Fig. 6a).

average slope of $0.028 \pm 0.007 \mathrm{~V}$ decade ${ }^{1}$ (Fig. 8b). In this case, for a constant $v$, the separation of the straight lines is about $-0.06 \mathrm{~V}$ decade $^{-1} \mathrm{NaOH}$ concentration. These relationships are, in principle, consistent

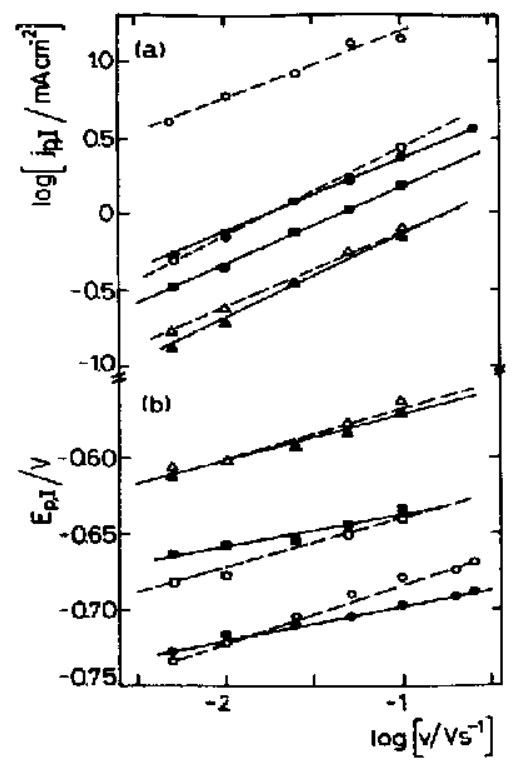

Fig. 8. Dependence of $v$ on $j_{p, I}$ (a) and $E_{p, 1}$ (b) from stabilized voltammograms. $E_{s . c}=-1.36 \mathrm{~V}$ and $E_{s, a}-0.24 \mathrm{~V}$ (dashed lines and open symbols); $E_{s, a}=-0.46 \mathrm{~V}$ (full lines and full symbols), $\omega=0$. $(0, \bullet) 1 \mathrm{M} \mathrm{NaOH} ;(\square, \square) 0.1 \mathrm{M} \mathrm{NaOH} ;(\Delta$, A) $0.01 \mathrm{M} \mathrm{NaOH}$.

with the participation of a diffusional process in the course of the anodic reaction.

For $0.01 \mathrm{M} \mathrm{NaOH}$, as $E_{s, u}$ is stepwise increased, the contribution III" in the voltammogram of cadmium under rotation appears as a hump at the positive potential side of the previously defined peak III (Fig. 9a) together with the gradual increases of the cathodic current at $E<-0.8 \mathrm{~V}$. The multiplicity of cathodic peaks becomes clearer in $1 \mathrm{M} \mathrm{NaOH}$ (Fig. 9b) where it appears that the anodic product firstly formed is

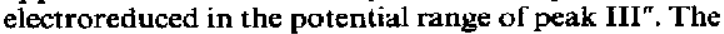
initial portion of the returning scan, including the contribution III", obeys a nearly linear current/potential relationship. The latter is no longer observed for $E_{s, a}$ either close to or greater than $E_{p, \text { II }}$ (Fig. 9b). Conversely, the initial anodic process in $0.01 \mathrm{M} \mathrm{NaOH}$ yields a product whose electroreduction is principally associated with peak III', whereas the anodic product related to the electroreduction process at peak III" is apparently electroformed as $E_{s, a}$ exceeds $E_{p, I}$. These results arc also consistent with the formation of soluble cadmium species simultaneously with the anodic cadmium hydroxide layer, at potentials more positive than $E_{p, I}$.

The complementary relationship between anodic and cathodic current peaks can be established more clearly at low $\mathrm{NaOH}$ concentration under stirring and low $v$, by increasing $E_{s . a}$ stcpwisc once a reasonably stable voltammogram has been attained. Thus, for $0.01 \mathrm{M} \mathrm{NaOH}$ in the voltammogram run between $-1.36 \mathrm{~V}$ and $-0.47 \mathrm{~V}$ at $v=0.004 \mathrm{Vs}^{-1}$ and $\omega$ $=2600 \mathrm{rpm}$ (Fig. 10) one notices that peak IV is related to the new small contributions $I^{\prime \prime}$ and III", and 


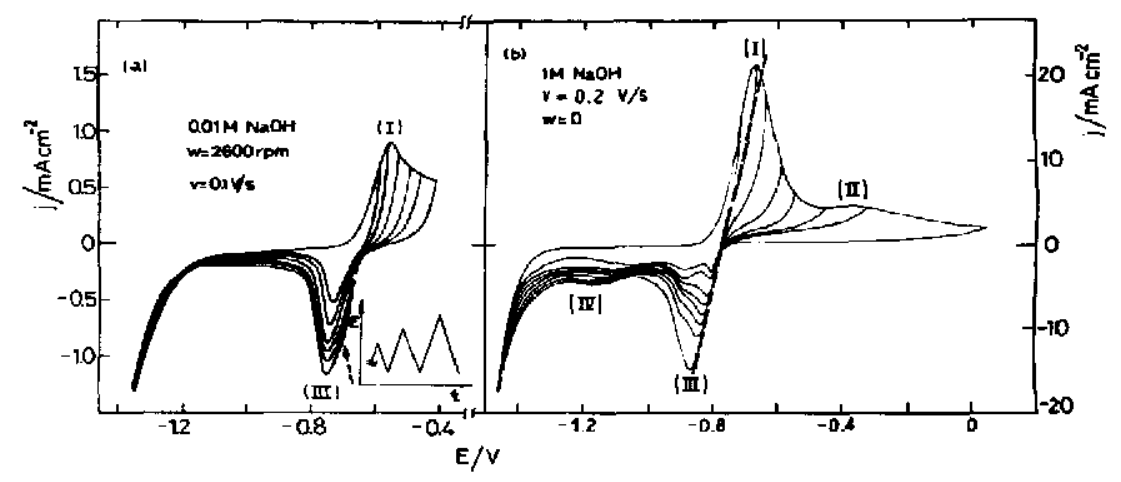

Fig. 9. Influence of increasing $E_{\text {s.e }}$ stepwise on the voltammograms. $v=0.1 \mathrm{Vs}^{-1}$, (a) $0.01 \mathrm{M} \mathrm{NaOH}, E_{s . c}=$ $-1.36 \mathrm{~V}, E_{s, a}=-0.6 \mathrm{~V}, \omega=2600 \mathrm{rpm}$. (b) $1 \mathrm{M} \mathrm{NaOH}, E_{s_{s, c}}=-1.46 \mathrm{~V}, E_{s_{1} a}=0.24 \mathrm{~V}, \omega=0$.

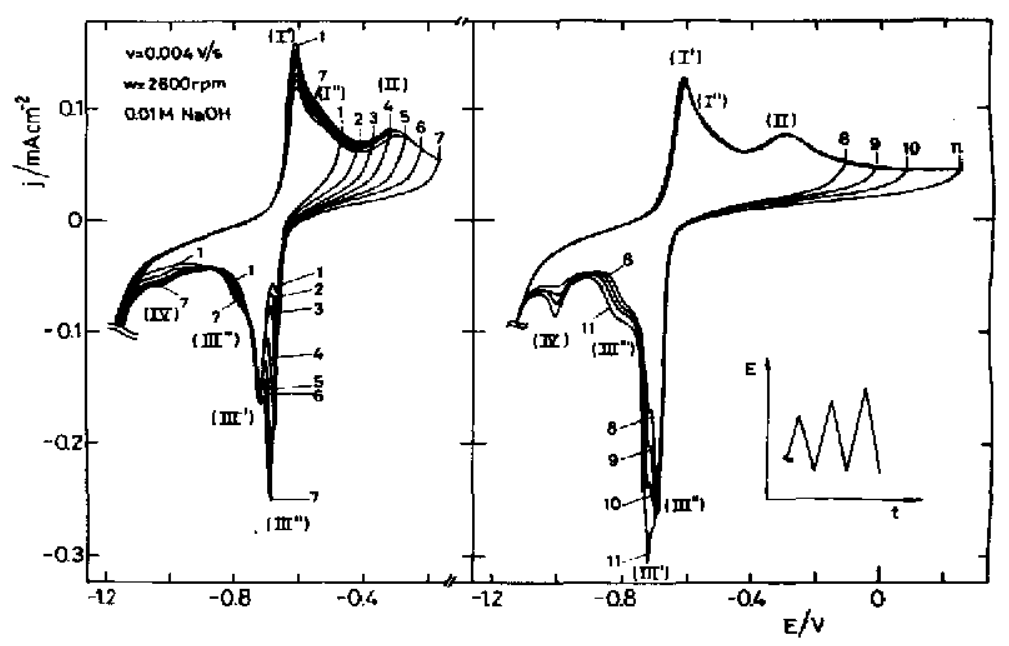

Fig. 10. Influence of increasing $E_{s .0}$ stepwise on the voltammograms, $v=0.004 \mathrm{Vs}^{-1}, 0.01 \mathrm{M} \mathrm{NaOH}, \omega$ $=2600 \mathrm{rpm}$. Runs include an RTPS between $E_{s_{s} a}=-1.36 \mathrm{~V}$ and $E_{x, a}=-0.46 \mathrm{~V}$ to attain the stabilized $E / j$ profile.

peak I' $^{\prime}$ is closely related to peak III'. Although peaks III', III" and III"' increase according to $E_{s, u}$ the relative height ratio of peaks III' and III" goes through a maximum as $E_{3, a}$ changes from $-0.5 \mathrm{~V}$ to $0.2 \mathrm{~V}$. The maximum contribution of peak III" results for $E_{s,}$ fixed in the neighbourhood of $E_{p, \mathrm{II}}$. Moreover, the height of peak IV definitely increases for $E_{s, a}>$ $-0.2 \mathrm{~V}$. On stepwise increasing $E_{s, a}$, the contribution of the cathodic sharp peak III" tends to disappear and the height of peak III' located at lower potentials increases. These results suggest a correlation between the amount of anodically formed layer and the electroreduction process.

Otherwise, at $v \geqslant 0.01 \mathrm{Vs}^{-1}$ and large $E_{s, a}$ values the sharp peak is no longer observed and it appears that the kinetics of the electrochemical processes become ohmic resistance controlled, in agreement with the tendency to $E_{p, 111} v s v^{1 / 2}$ and $j_{p \text {, III }} v s v^{1 / 2}$ linear relationships (Fig. 11). In this case, a straight line with a common slope can be drawn for both the anodic and the cathodic processes in the neighbourhood of $-0.8 \mathrm{~V}$ (dashed line in Fig. 9b). The parameter $R$ $=\left(\partial E_{p, \mathrm{UI}} / \partial v^{1 / 2}\right)_{\mathrm{pH}} /\left(\partial j_{\mathrm{p}, \mathrm{III}} / \partial v^{1 / 2}\right)_{\mathrm{pH}}$ increases twice for tenfold decreasing the concentration of $\mathrm{NaOH}$.

Analogously, voltammetric runs made by stepwise decreasing $E_{s, c}$ show that the electrooxidation charge for $E_{s, c}<-0.9 \mathrm{~V}$ becomes independent of $E_{s, c}(\mathrm{Fig}$. 12). On the other hand, for $E_{s, c}>-0.9 \mathrm{~V}$, the voltammogram exhibits only the partial electrorcduction of the anodic layer, the relative enhancement of contribution III", and the prevailance of peak II in the anodic potential scan (Figs 12 and 13). These results indicale that the amount of soluble cadmium species formed during the positive potential scan becomes practically independent of the resulting anodic layer. Furthermore, for $E_{s, c}$ more positive than $E_{p, \text { III }}$, and 
particularly at low $v$ it is clear that the current/potential profiles practically coincidc, independently of the dircetion of the potential scan. These profiles also obey reasonable linear $j / E$ relationships (Fig. 13).

From the voltammetric data one concludes that the electroformation of soluble cadmium in the overall anodic reaction becomes comparatively smaller than that of the anodic layer as the concentration of $\mathrm{NaOH}$ decreases. Therefore, it seems that the results obtained at lower $\mathrm{NaOH}$ concentration bring forth the most reliable information concerning the electroformation of the anodic layer itself.

Voltammetric data resulting from combined TPS and potential step

The formation of soluble cadmium species is confirmed by running voltammograms under rotating

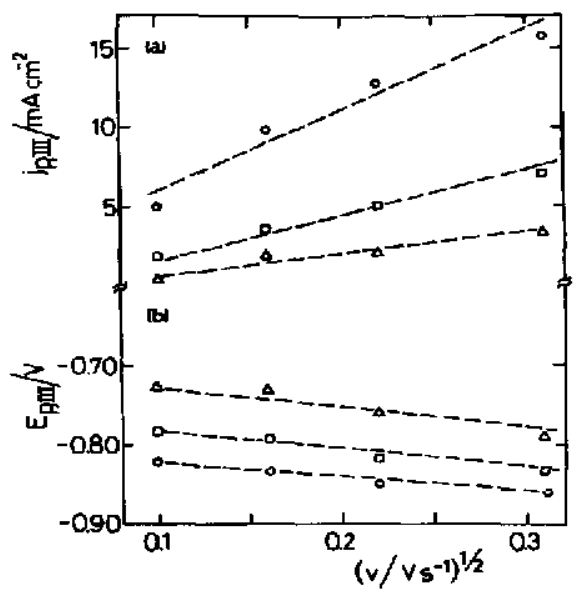

Fig. 11. Dependence of $v$ on $j_{p \text { III }}$ (a) and $E_{p, \text { III }}$ (b) from voltammograms nun between $E_{x, \mathrm{c}}=-1.36 \mathrm{~V}$ and $E_{\mathrm{x}}$ $=0.24 \mathrm{~V}$ at $\omega=0$. (o) $1 \mathrm{M} \mathrm{NaOH}$; (口) $0.1 \mathrm{M} \mathrm{NaOH;} \mathrm{( \Delta )}$ $0.01 \mathrm{M} \mathrm{NaOH}$ cadmium discs including a potential step at $E_{\star}$, during the time $\tau$, in the course of the anodic potential scan (Fig. 14). After the potential holding at $E_{\tau}=-0.66 \mathrm{~V}$ the continuing potential scan shows a decrease, according to $\tau$, in the anodic charge and an appreciable increase in cathodic current for $E<-1.0 \mathrm{~V}$ (Fig. 14a). As $E_{t}$ is set increasingly positive, firstly peak $I$ and later peak II disappear, whereas the cathodic current for $E$ $<-1.0 \mathrm{~V}$ increases according to $E_{\tau}$ (Fig. 14b). Likewise, for $E_{\tau}=0.14 \mathrm{~V}$ the charge of peak $11 \mathrm{I}$ appreciably increases and $E_{p \text {.II }}$ shifts more negatively, whereas the cathodic current for $E<-1.0 \mathrm{~V}$, after baseline correction for peak III, remains apparently unchanged (Fig. 14c). Simjlar experiments carried out with still electrodes including a potential step in the negative potential scan (Fig. 15) reveal an increase in the charge of peak III as $E_{\tau}$ is changed from $-0.72 \mathrm{~V}$ up to $\mathrm{ca}-0.6 \mathrm{~V}$, and a nearly constant charge for $E_{c}$ $>0.6 \mathrm{~V}$. The cathodic current for $E<-1.0 \mathrm{~V}$ definitely increases according to $E_{z}$.

The RTPS voltammogram for $0.01 \mathrm{M} \mathrm{NaOH}$ run from $E_{s, c}$ to $E_{s, a}$ can be modified just by changing only $E_{s, c}$ during a certain time $t$ to a new value $E_{s, c}^{\prime}$ located within the potential range of peak III, and later recording again the voltammogram between $E_{s . a}$ and

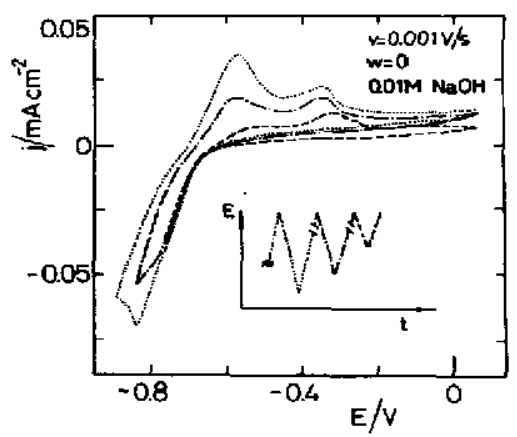

Fig. 13. Influence of $E_{s, c}$ on the stabilized voltammograms, $v$ $=0.001 \mathrm{Vs}^{-1}, 0.01 \mathrm{M} \mathrm{NaOH}, \omega=0 . E_{s, a}=0.06 \mathrm{~V}$

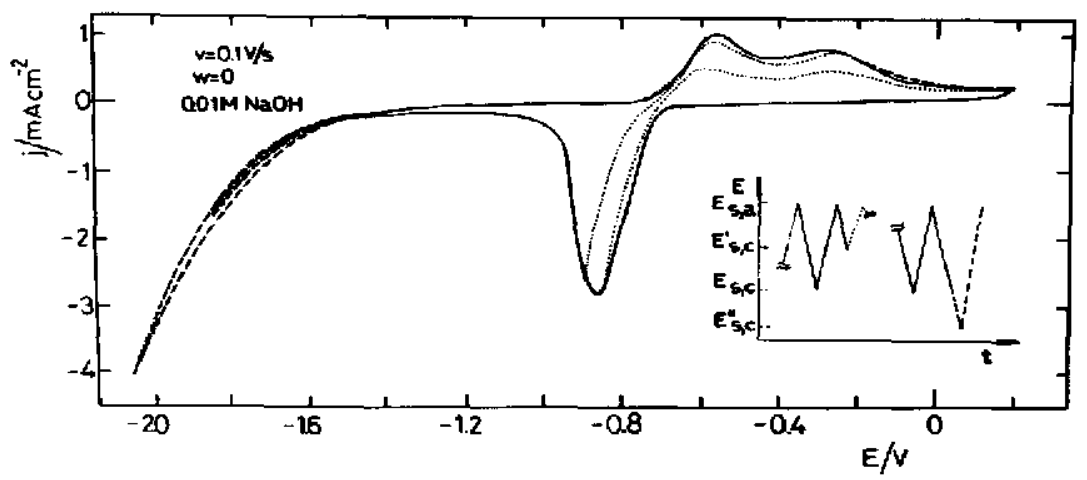

Fig. 12. Influence of changing $E_{\text {, c }}$ stepwise either upwards (dotled curves) or downwards (dashed curves) on the voltammograms run at $v=0.1 \mathrm{~V} \mathrm{~s}^{-1}, 0.01 \mathrm{M} \mathrm{NaOH}, \omega=0$. Runs include a previous RTPS between $E_{s, r}$ $=-1.36 \mathrm{~V}$ and $E_{s, a}=0.19 \mathrm{~V}$ to attain the stabilized profile. 


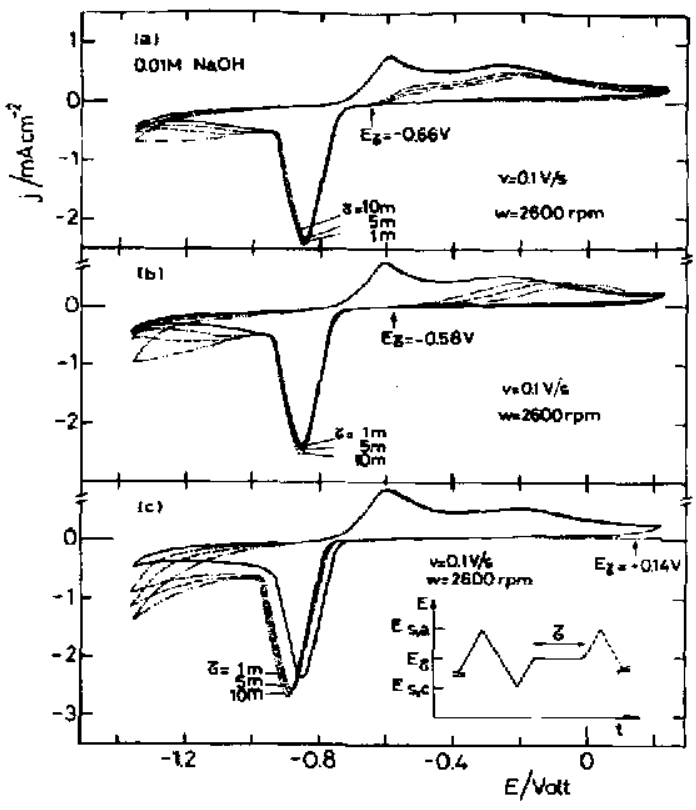

Fig. 14. Influence of $E_{\mathrm{r}}$ and $\tau, v=0.1 \mathrm{Vs}^{-1}, 0.01 \mathrm{M} \mathrm{NaOH}$, $\omega=2600 \mathrm{rpm}$. (a) $E_{\mathrm{r}}=-0.66 \mathrm{~V}$; (b) $E_{\mathrm{r}}=-0.58 \mathrm{~V}$; (c) $E_{\mathrm{r}}$ $=0.14 \mathrm{~V}$. The potential programme applied to the electrode is shown in the figure.

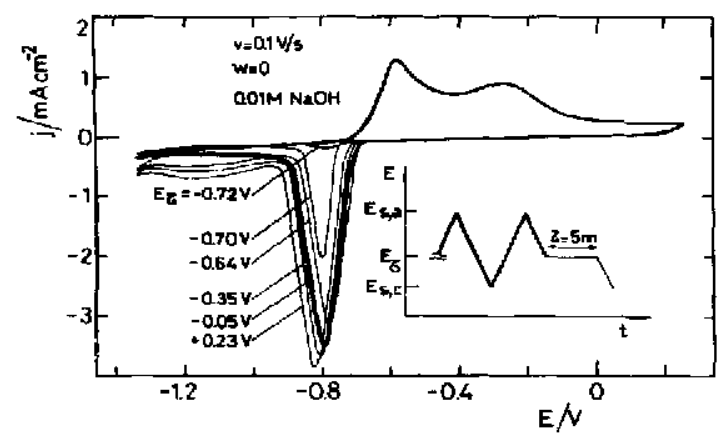

Fig. 15. Influence of $E_{\mathrm{r}}$ for $\tau=5 \mathrm{~min}, 0.1 \mathrm{Vs}^{-1}, 0.01 \mathrm{M}$ $\mathrm{NaOH}, \omega=0$. The potential programme applied to the electrode is shown in the figure.

$E_{\text {s.c }}$ for comparison to the initial RTPS voltammogram (Fig. 16). For $E_{s, c}^{\prime}$ more negative than $E_{p, \text { III }}$ the intermediate RTPS from $E_{s, u}$ to $E_{s, c}^{\prime}$ only increascs the cathodic current for $E<-1.0 \mathrm{~V}$ (Fig. 16a), but as $E_{s, c}^{\prime}$ is set closer to $E_{p_{r} \mathrm{II}}$, peak III appears as a double peak and the cathodic current for $E<1.0 \mathrm{~V}$ substantially increases (Fig. 16b). Finally, on increasing further $E_{s, c}$ to a value located near to the extreme of peak III (Fig. 16c) the double peak disappears, peak III definitely shifts about $0.1 \mathrm{~V}$, and the cathodic current for $E<1.0 \mathrm{~V}$ increases practically to the same value as above mentioned for $E_{s . c}^{\prime}=-0.89 \mathrm{~V}$. In this case, the

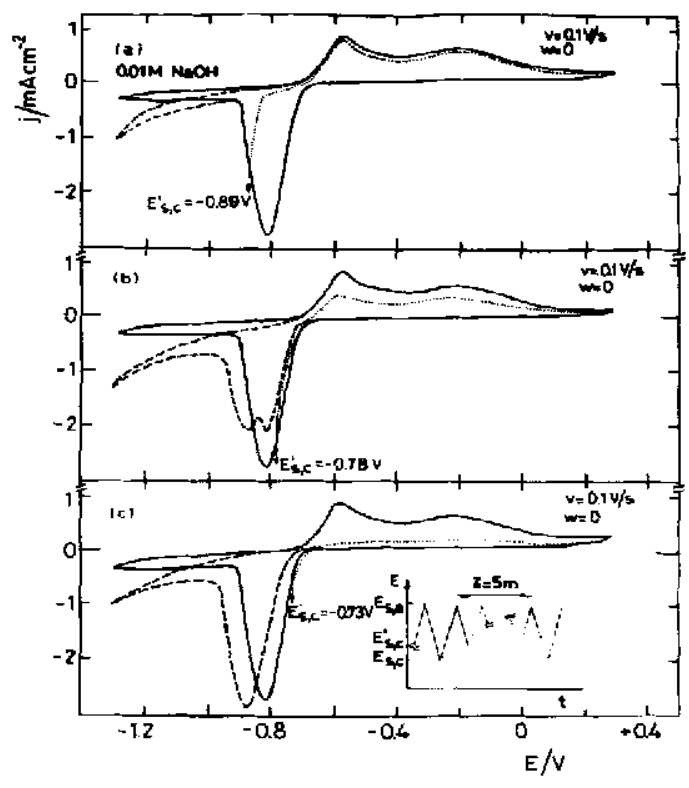

Fig. 16. Voltammetric response after applying the potential programme indicated in the figure. Stabilized voltammogram (full trace), $n=0.1 \mathrm{Vs}^{-1}, E_{s_{1},}=-1.30 \mathrm{~V}, E_{\mathrm{s}, a}=0.24 \mathrm{~V}$, $0.01 \mathrm{M} \mathrm{NaOH}, \omega_{2}=0$. TPS between diffierent $E_{s, c}^{\prime}$ values and $E_{s, a}$ (dotted line). Voltammograms after $5 \mathrm{~min}$ potentiodynamic ageing (dashed line). (a) $E_{s, \mathrm{c}}^{\prime}=-0.89 \mathrm{~V}$; (b) $E_{\text {s.c }}^{\prime}=$ $-0.78 \mathrm{~V}$; (c) $E_{s, c}^{\prime}=-0.73 \mathrm{~V}$.

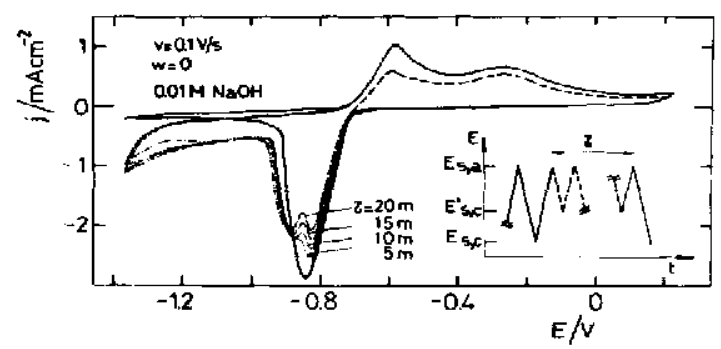

Fig. 17. Voltammetric response after applying the potential programme shown in the figure. Stabilized voltammogram (full trace), $0.1 \mathrm{Vs}^{-1}, E_{s, c}=-0.136 \mathrm{~V}, E_{s, a}=0.24 \mathrm{~V}, 0.01 \mathrm{M}$ $\mathrm{NaOH}, \omega=0$. Voltammograms after potentiodynamic ageing during $\tau$ between $E_{s, c}^{\prime}=-0.82 \mathrm{~V}$ and $E_{s .0}$ (dashed lines).

potential of the corresponding clectroreduction peak coincides with that of the current peak component shown in Fig. 16b, located at the negative potential side. The splitting of peak III into peaks III' and III" resulting after the combined potentiodynamic cycling for $E_{s, r}^{\prime}=-0.81 \mathrm{~V}$ depends on $\tau$ (Fig. 17). It appears that the charge of peak III' increases at the expense of that of peak $111^{\prime \prime}$. Furthermore, the cathodic current for $E<-1.0 \mathrm{~V}$ firstly approaches a limiting value and later defines a broad peak at $c a-1.1 \mathrm{~V}$.

The same effects can be observed under comparable conditions in $1 \mathrm{M} \mathrm{NaOH}$ (Fig. 18), except that in this 


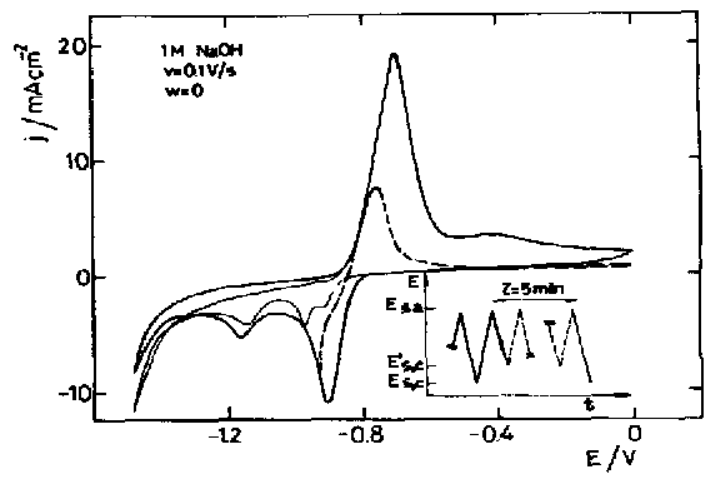

Fig- 18. Voltammetric profiles after applying the potential programme depicted in the figure. Stabilized voltammogram (full trace), $v-0.1 \mathrm{~V} \mathrm{~s}^{-1}, E_{s, c}=-1.46 \mathrm{~V}, E_{s, a}=0.04 \mathrm{~V}$, $1 \mathrm{M} \mathrm{NaOH}$. After the potentiodynamic ageing for $\tau=5 \mathrm{~min}$ (dashed trace).

case the charge associated with the passivating layer decreases, the electroreduction potential of the passivating layer shifts about $0.1 \mathrm{~V}$ more negative, and the electroreduction current for $E<-1.3 \mathrm{~V}$, results substantially increased. Therefore, the anodic layer produced through the combined potentiodynamic cycling turns out more stable than that formed under conventional voltammetry.

\section{TMTPS voltammetry}

The reversible characteristics of the initial stages of the electrooxidation reaction are confirmed through TMTPS voltammetry. The single triangularly modulated anodic scan shows nearly symmetric anodic and cathodic current contours at potentials slightly greater than the reversible potential of the $\mathrm{Cd} / \mathrm{Cd}(\mathrm{OH})_{2}$ electrode (Figs 19 and 20 ). In addition, these runs also show that as $E_{s, \triangleleft}$ enters the potential range of peak I, the latter splits into two peaks whose potentials are separated by about $0.2 \mathrm{~V}$.

\section{Potentiostatic transients}

The potentiostatic transients related to the electroreduction of the anudic layer formed in the potential range of peak III, exhibit two different behaviours depending on whether the value of the potential steps, $E_{f}$, is greater than $-0.7 \mathrm{~V}$ or lower than $-0.86 \mathrm{~V}$, or it lies in the intermediate range (Fig. 21). In the two former cases current transients comprise a single maximum, $j_{M}$, at $t_{M}$. But in the intermediate range morc complex current transients are obtained which can be associated, in principle, with the occurrence of two simultaneous electroreduction processes with appreciably different reaction rates.

The current transients with a single maximum are strongly stirring dependent, presumably because they are associated with the reaction of soluble cadmium, whereas the complex current transients in the intermediate potential range correspond, principally, to the electroreduction of both the anodic layer and soluble cadmium species. The current transients exhibit a nearly constant $J_{M} t_{M} / Q_{M}(\simeq 1.08)$ value (Fig. 22a) and a linear $\log j_{M}$ ws $\log t_{M}$ relationship whose slope is close to -2 (Fig. 22b).

\section{Rrde experiments}

Rrde experiments confirm the generation of soluble cadmium species already at potentials close although more negative than $E_{p . f}$, corresponding to the initial stage of the anodic film formation (Fig. 23). At high positive potentials the chemical dissolution of the anodic layer is noticed (Fig. 23a). Soluble cadmium species are also detected within the potential range of the peaks I and III, the amount of metal dissolution in the case being considerably smaller than that found previously (Fig. 23b).

\section{DISCUSSION}

Voltammetric results of cadmium anodization in $\mathrm{NaOH}$ solutions show various complex processes which are differently influenced by $v$ and $\omega$. At any $\mathrm{NaOH}$ concentration a noticeable influence of $v$ is obscrved through the decrease in the anodic polarization and the increase in the anodic charge as $v$ decreases. The anodic reaction yields simultaneously the formation of a new phase and the appearance of soluble cadmium species, the relative yielding of the latter increases according to the concentration of $\mathrm{NaOH}$. Otherwise, the cathodic reactions also comprise various complex processes which are influenced by both $\omega$ and $v$. The reactions involving the electroreduction of soluble species are those most strongly dependent on $a$.

The potential associated with the anodic process and its dependence on $\mathrm{NaOH}$ concentration, corresponds to the reaction:

$$
\mathrm{Cd}(\mathrm{s})+2 \mathrm{OH}^{-} \rightleftharpoons \mathrm{Cd}(\mathrm{OH})_{2}(\mathrm{~s})+2 e^{-} .
$$

The standard equilibrium potential of reaction (1) at $25^{\circ} \mathrm{C}$ is $-0.824 \mathrm{~V}[29]$. Reaction (1), as expected from its applications of cadmium electrodes in cells and batteries, behaves as a reversible reaction (Figs 3, 19 and 20 ).

The inspection of equilibrium potentials related to different reactions of cadmium in aqueous solutions (Table 1) shows that the formation of $\mathrm{CdO}$ according to:

$$
\mathrm{Cd}(\mathrm{s})+2 \mathrm{OH}^{-} \rightleftharpoons \mathrm{CdO}(\mathrm{s})+\mathrm{H}_{2} \mathrm{O}+2 e^{-}
$$

is only $41 \mathrm{mV}$ more positive than that of reaction (1). In addition, the higher the $\mathrm{pH}$ of the solution the potentials of those reactions yielding soluble cadmium species [reactions (3) and (4)] become closer to those of reactions (1) and (2). Therefore, from the thermodynamic standpoint the formation of soluble cadmium species as well as that of solid $\mathrm{Cd}(\mathrm{OH})_{2}$ and $\mathrm{CdO}$ phases can already take place within the potential range of peak 1 . Furthermore, the values of the isoelectric point of $\mathrm{Cd}(\mathrm{OH})_{2}(>10.5)$ and $\mathrm{CdO}(10.4$ $\pm 0.2)[30]$ indicate that the corresponding hydrous structures are stable at nearly the same pH and they both should involve an excess of $\mathrm{OH}^{-}$inns.

The complex overall process has been alternatively explained in terms of dissolution/precipitation mec- 


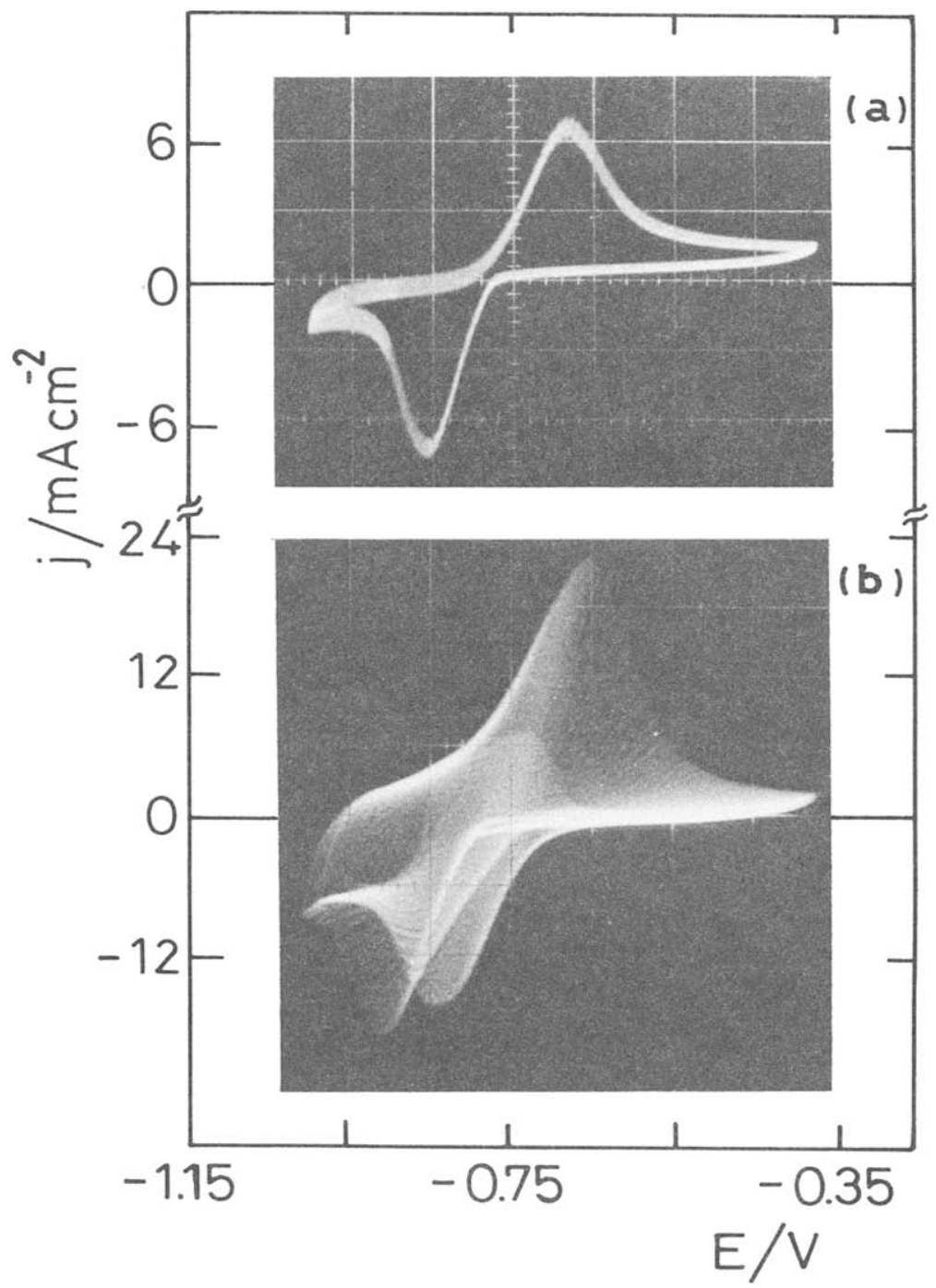

Fig. 19. Comparison between RTPS voltammograms and TMTPS contours, $1 \mathrm{M} \mathrm{NaOH}$ (a) $v=0.5 \mathrm{~V} \mathrm{~s}^{-1}$; (b) $v_{\mathrm{g}}=0.5 \mathrm{~V} \mathrm{~s}, v_{m}=40 \mathrm{~V} \mathrm{~s}^{-1}, A_{m}=0.2 \mathrm{~V}$.

hanisms[42], active dissolution prior to film formation through solid state reaction [43] and the presence of a extremely supersaturated unstable solution [44]. These interpretations, however, were satisfactory under a relatively limited range of experimental conditions.

Let us firstly consider the kinetics of the entire anodic reaction. All processes taking place in the potential range of peak I should start as a surface reaction at the monolayer level with the simultaneous trend to decrease in $\mathrm{pH}$ at the interface, namely a $\mathrm{pH}$ gradient through the anodically formed layer. Presumably reaction (1) is the sum of two consecutive one-electron stage processes, namely:

$$
\begin{gathered}
\mathrm{Cd}(\mathrm{s})+\left(\mathrm{OH}^{-}\right)_{\mathrm{i}} \rightleftharpoons \mathrm{Cd}(\mathrm{OH})_{\mathrm{ad}}+e^{-} \\
\mathrm{Cd}(\mathrm{OH})_{\mathrm{ad}}+\left(\mathrm{OH}^{-}\right)_{\mathrm{i}} \rightleftharpoons \mathrm{Cd}(\mathrm{OH})_{2}(\mathrm{~s})+e^{-}
\end{gathered}
$$

where the subscripts $i$ and ad denote ionic species at the compact double layer region and adsorbed species, respectively. The occurrence of reaction (1a) can be sustained from the electrochemical kinetic data of a large number of transition metals in aqueous alkaline solutions [31-38] and particularly for cadmium in acidic solutions [39], its reaction rate being faster than those of the following stages. Likewise, pseudocapacitance measurements suggest that the adsorption of $\mathrm{OH}$ species precedes the potential range of the possible formation of $\mathrm{Cd}(\mathrm{OH})_{2}[40]$. It should be noticed, however, that in contrast the reactivity of scratched cadmium electrodes in alkaline solutions has been interpreted in terms of simultaneous transfer of two electrons[41], but it appears that the kinetic data resulting from the transicnt electrochemical behaviour 


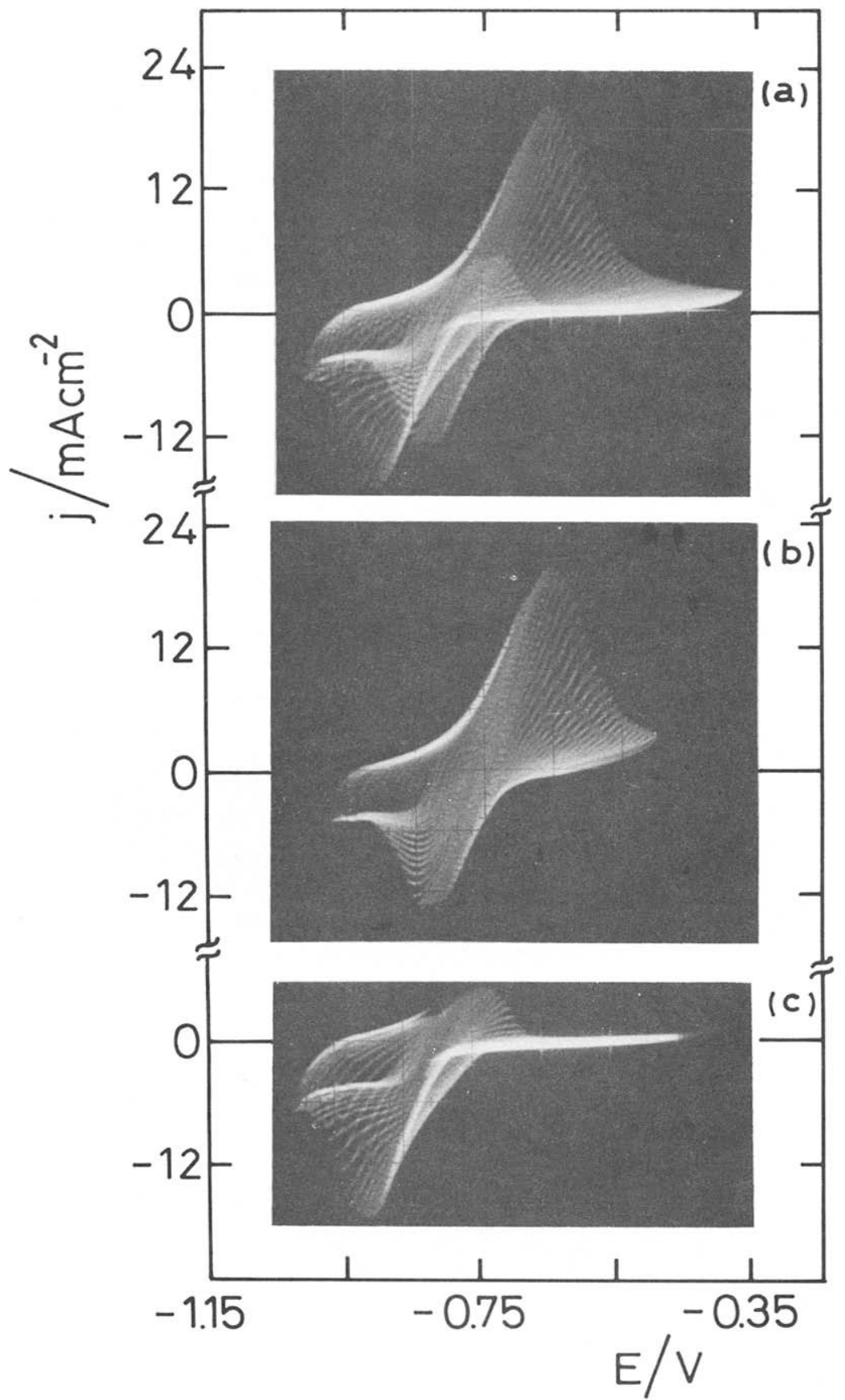

Fig. 20. (a) TMTPS contours, $1 \mathrm{M} \mathrm{NaOH}, v_{a}=0.5 \mathrm{Vs}^{-1}, v_{m}=20 \mathrm{~V} \mathrm{~s}^{-1}, A_{m}=0.15 \mathrm{~V}$; positive (a) and negative (b) potential going TMTPS scans corresponding to the display (a).

of freshly generated surfaces by the scratching technique are insufficient to disregard the formation of a $\mathrm{Cd}(\mathrm{I})$ intermediate if the electrodissolution reaction is a rather complex process. For the present case, however, as the different processes appear without any appreciable activation polarization, one can only admit that the rate of reaction (1a) is at least as fast as that of reaction (1b). Then, for describing the kinetics of the anodic reaction, one can ascribe a common reactant at the surface for the different reactions such 


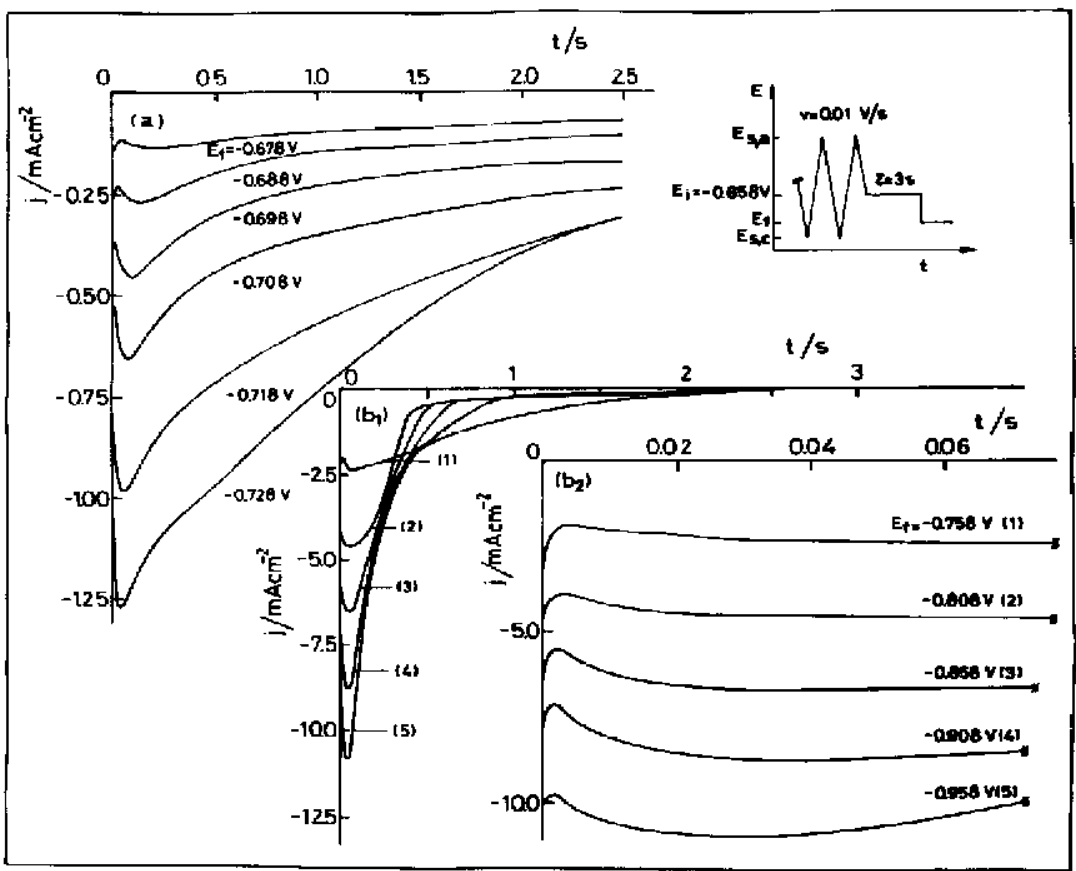

Fig. 21. Cathodic current transients for $E_{i}=-0.658 \mathrm{~V}$ up to different $E_{f}$ values. $v=0.01 \mathrm{~V} \mathrm{~s}^{-1}, E_{s, c}=$ $-1.36 \mathrm{~V}, E_{s, 4}=0.24 \mathrm{~V}, 0.01 \mathrm{M} \mathrm{NaOH}, \omega=0$. The stabilized voltammogram was obtained before the potentiostatic current was recorded.

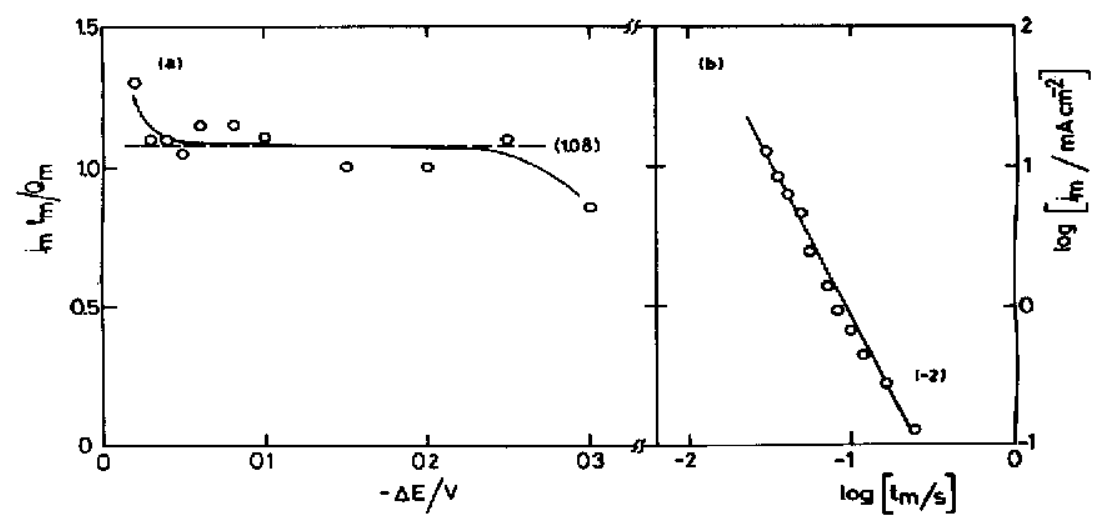

Fig. 22. $j_{m} t_{m} v s Q_{m}$ (a) and $\log j_{m} v s \log t_{m}$ (b) plots from the cathodic current transients obtained by applying the potential programme drawn in Fig. 21.

as $\mathrm{Cd}(\mathrm{OH})_{\mathrm{ad}}$ which is supplied through reaction (1a). Then, in principle, the possibility of forming different products should mainly depend on the $\mathrm{OH}$ ion concentration available at the reaction site, namely in contact with $\mathrm{Cd}(\mathrm{OH})_{\text {ad }}$, or if the reaction has already occurred for a certain time, on the $\mathrm{OH}^{-}$ion concentration within the anodically formed layer. These reactions are:

$$
\mathrm{Cd}(\mathrm{OH})_{\mathrm{ad}}+\left(\mathrm{OH}^{-}\right)_{i} \rightleftharpoons \mathrm{Cd}(\mathrm{OH})_{2}(\mathrm{~s})+e^{-}
$$

$$
\begin{aligned}
\mathrm{Cd}(\mathrm{OH})_{\mathrm{ad}} & \rightleftharpoons \mathrm{CdO}(\mathrm{s})+\left(\mathrm{H}^{+}\right)_{\mathrm{i}}+e^{-} \\
\left.\mathrm{L}^{+} \mathrm{H}^{+}\right)_{\mathrm{i}}+\left(\mathrm{OH}^{-}\right)_{\mathrm{i}} & \left.\rightleftharpoons \mathrm{H}_{2} \mathrm{O}\right] \\
\mathrm{Cd}(\mathrm{OH})_{\mathrm{ad}}+2\left(\mathrm{OH}^{-}\right)_{i} & \rightleftharpoons \mathrm{Cd}(\mathrm{OH})_{3}^{-}+e^{-} \\
\mathrm{Cd}(\mathrm{OH})_{3}^{-}+\left(\mathrm{OH}^{-}\right)_{\mathrm{i}} & \rightleftharpoons \mathrm{Cd}(\mathrm{OH})_{4}^{2-} \\
\mathrm{Cd}(\mathrm{OH})_{\mathrm{ad}}+3\left(\mathrm{OH}^{-}\right)_{\mathrm{i}} & \rightleftharpoons \mathrm{Cd}(\mathrm{OH})_{4}^{2-}+e^{-} \\
\mathrm{Cd}(\mathrm{OH})_{\mathrm{ad}} & \rightleftharpoons \mathrm{CdOH}^{+}+e^{-} \\
\mathrm{CdOH}^{+} & \rightleftharpoons \mathrm{Cd}^{2+}+\mathrm{OH}^{-}
\end{aligned}
$$




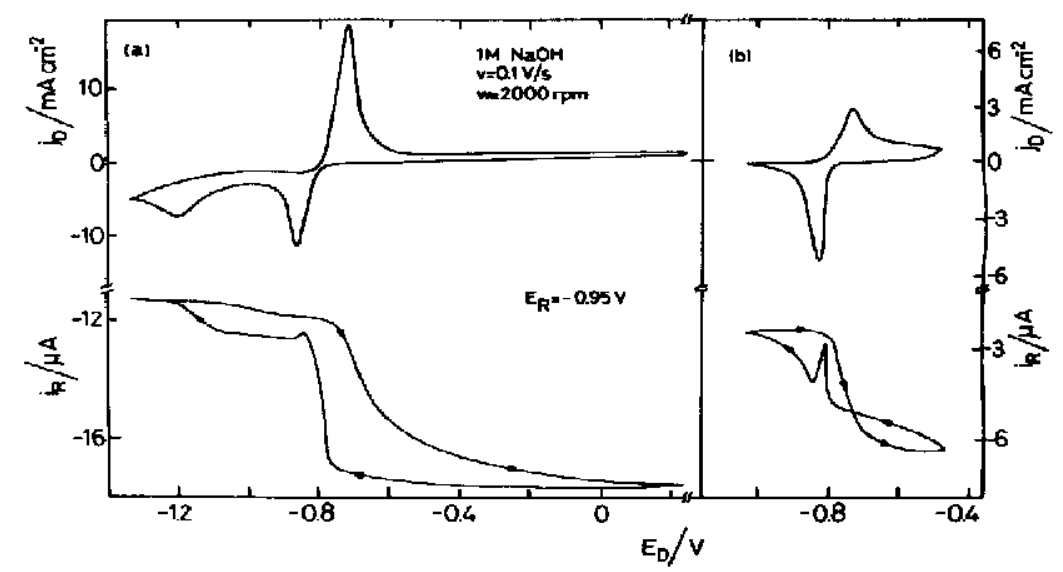

Fig. 23. Ring and disc currents vs disc potential plots. $v=0.1 \mathrm{~V} \mathrm{~s}^{-1}, \omega=2000 \mathrm{rpm}, E_{\mathrm{r}}--0.95 \mathrm{~V}, 1 \mathrm{M}$ $\mathrm{NaOH}$. (a) $E_{s, c}=-1.36 \mathrm{~V}, E_{\mathrm{s}, \mathrm{s}}=0.24 \mathrm{~V}$; (b) $E_{s, c}=-1.06 \mathrm{~V}, E_{s, a}=-0.46 \mathrm{~V}$.

Table 1. Standard potentials and equilibrium potentials at pH 12 of cadmium electrode reactions at $25^{\circ} \mathrm{C}[29]$

\begin{tabular}{lcc}
\hline \multicolumn{1}{c}{ Rencliun } & $E^{0}(\mathrm{~V})$ & $E_{\mathrm{pH}-12}(\mathrm{~V})$ \\
$\mathrm{Cd}(\mathrm{OH})_{2}(\mathrm{~s})+2 e \rightleftharpoons \mathrm{Cd}+2 \mathrm{OH}$ & -0.824 & -0.706 \\
$\mathrm{CdO}(\mathrm{s})+\mathrm{H}_{2} \mathrm{O}+2 e \rightleftharpoons \mathrm{Cd}+2 \mathrm{OH}$ & -0.783 & -0.665 \\
$\mathrm{Cd}(\mathrm{OH})_{3}^{-}+2 e^{-} \rightleftharpoons \mathrm{Cd}+3 \mathrm{OH}^{-}$ & -0.668 & $-0.668^{*}$ \\
$\mathrm{Cd}(\mathrm{OH})_{4}^{2}+2 e^{-} \rightleftharpoons \mathrm{Cd}+4 \mathrm{OH}^{-}$ & -0.670 & $-0.620^{*}$ \\
$\mathrm{Cd}^{2}+2 e \rightleftharpoons \mathrm{Cd}$ & -0.402 & $-0.705^{*}$
\end{tabular}

* Calculated for $\mathrm{Cd}(\mathrm{OH})_{2}$ saturation condition[59].

The participation of soluble Cd(II) species just from the initial electrooxidation process has been clearly detected in rrde measurements (Fig. 23).

At a constant overvoltage, the kinetics of all these reactions is determined by their corresponding reaction order with respect to $\mathrm{OH}^{-}$ion at the reaction site, as it should be determined by the rate of transport of $\mathrm{OH}^{-}$ions from the bulk of the solution. Furthermore, the entire process should also become even more complex because of the different ionic and solubility equilibria conditioning the structure of the anodic layer, as may be the case for soluble species formed through chemical reactions occurring at a certain distance from the actual reaction site, as represented by reactions such as:

$$
\begin{aligned}
& \mathrm{Cd}(\mathrm{OH})_{2}(\mathrm{~s})+\left(\mathrm{OH}^{-}\right)_{i} \rightleftharpoons \mathrm{Cd}(\mathrm{OH})_{3}^{-} \\
& \mathrm{Cd}(\mathrm{OH})_{2}(\mathrm{~s})+2\left(\mathrm{OH}^{-}\right)_{i} \rightleftharpoons \mathrm{Cd}(\mathrm{OH})_{4}^{2-}
\end{aligned}
$$

Analogously reactions (6) and (7) in the reverse direction can contribute to the thickening of the anodic layer.

On the basis of this reaction model it comes out immediately that the influence of stirring on the entire anodic process should be negligible as the transport of $\mathrm{OH}^{-}$ion concerns principally with diffusion through the anodic layer. Conversely, as the reaction timc increases (lower $v$ ) the extent of the anodic processes, particularly those related to reactions (3a) and (4a), should be enhanced. These contributions should be dircctly proportional to $\mathrm{NaOH}$ concentration. Hence, the increase in the height of peak $I$ on $t^{1 / 2}(\mathrm{Fig} .8 \mathrm{a}) \mathrm{can}$ be cxplained as a diffusion controlled process occurring through the anodic layer, and also the dependence of the peak potential on $v$ (Fig. 8b) can be principally caused by a local change in $\mathrm{pH}$ which in turn is also $v$ dependent. Soluble species can either remain inserted into the growing anodic layer or diffuse out into solution. In this respect, both $v$ and $\omega$ should influence the amount and distribution of soluble product. Accordingly, the accumulation of anodic charge in $1 \mathrm{M}$ $\mathrm{NaOH}$ diminishes considerably as the electrolyte solution is previously saturated with $\mathrm{CdSO}_{4}$.

The formation of $\mathrm{CdO}$ which has been detected by different optical methods[45-47] should become increasingly relevant as $v$ decreases and $\mathrm{OH}$ ion concentration increases. The CdO layer should appear as the inner part of the anodic layer and its formation should increase parallel to the appearance of soluble cadmium species. This situation correlates with the following facts observed as $v$ decreases and the concentration of $\mathrm{OH}^{-}$increases: (i) the cathodic current at potentials more negative than $-0.9 \mathrm{~V}$ increases; (ii) the height of peak III' increases; (iii) the potential for the initiation of peak III' $^{\prime}$ is practically coincident to that of reaction (2); and (iv) the appearance of peak III $^{\prime}$ corresponds to an increase in sharpness of peak $I$ and its shift to potentials closer to the reversible potential 
of reaction (2). The foregoing discussion is also consistent with a gel-like anodic layer structure whose stability depends on the intercalation of $\mathrm{OH}^{-}$ion as required according to the isoelectric point of the species involved[30].

The participation of reactions (3) and (4) in the overall anodic rcaction remains up to the potential where the anodic layer acquires the characteristics of a passivating film[2-5], probably by a drastic decrease of its water content through electrochemical deprotonation. This explanation is also coherent with the fact that at low NaOII concentration there is an intermediate potential range where the formation of soluble cadmium species reaches a maximum value.

Further changes in the characteristics of the anodic layer after its anodization at relatively large positive potentials are detected through its electroreduction voltammogram under different combined potential programs (Figs 9b, 14 and 15). In this case, peak II keeps a relatively small and constant charge which is, in principle, independent of the NaOH concentration, but both the amount of soluble cadmium species and the charge of pcak III are appreciably increased. Accordingly, after the combined TPS and potential step program, peak III becomes broader and shifted towards more negative potentials. The corresponding electroreduction cycle run immediately afterwards points out to a greater stability of the overall anodic layer. This effect is similar to ageing effects previously discussed for other hydrous metal hydroxide layers [28, 48-53], and it can be explained through a decrease in the water content of the anodized layer. Under extreme polarization conditions the properties of the anodic layer correspond to that of a true passive layer (Fig. 4). The degree of passivity is afforded by the slope of the initial portion of peak III, which fits a linear potential/current relationship, independently of the anodic charge. In this case, the electroreduction process should involve an appreciable ohmic polarization contribution in agreement with the $E_{p, \text { III }}$ vs $v^{1 / 2}$ and $j_{p, \text { w }}$ es $v^{1 / 2}$ relationships (Fig. 11).

On the other hand, the overall cathodic reaction concerns with the following reactions appearing as the potential is continuously lowered from $E_{s, a}$ to $E_{s, c}$.
Firstly, the electroreduction of the hydrous $\mathrm{CdO}$ layer presumably occurs in the potential range of peak III'. The kinetics of this process can be explained through a nucleation and growth mechanism associated with a reaction such as:

$$
\mathrm{CdO} \text { (hydrous) }=\mathrm{Cd}(\mathrm{OH})_{2} \text { (hydrous). }
$$

The shape of peak III' and the current transients at constant potential, in principle, favour this explanation, although for deriving a more sound conclusion further experimental information is required. A strong competition between $\mathrm{CdO}$ reduction, $\mathrm{CdO}$ hydration and reduction and dissolution of $\mathrm{Cd}(\mathrm{OH})_{2}$ likely occurs [54]. Otherwise, in the potential range of peak III the electroreduction of the $\mathrm{Cd}(\mathrm{OH})_{2}$ hydrous layer takes place. This reaction presumably involves the participation of two reactants, namely a non-aged and an aged species, the latter resulting from a loss of water represented through a process of the following type:

$$
\begin{aligned}
& {\left[\mathrm{Cd}(\mathrm{OH})_{2} \times \mathrm{H}_{2} \mathrm{O}\right] \rightarrow} \\
& \left.\qquad \mathrm{Cd}(\mathrm{OH})_{2} x^{\prime} \mathrm{H}_{2} \mathrm{O}\right]^{*}+\left(x-x^{\prime}\right) \mathrm{H}_{2} \mathrm{O}
\end{aligned}
$$

where the asterisk denotes the aged species. It appears that the non-aged reactant participates in a fast electron transfer with an appreciable ohmic polarization contribution. On further decreasing the potential from $-1.0 \mathrm{~V}$ to $-1.2 \mathrm{~V}$, the electroreduction of soluble cadmium species takes place yielding a cadmium surface in contact with the base electrolyte. This process involves a large convective diffusion contribution as the limiting current changes linearly with both $v^{1 / 2}$ and $\omega^{1 / 2}$ Finally, at potentials more negative than $-1.2 \mathrm{~V}$ the HER takes place, probably on a cadmium electrode covered by a thin $\mathrm{Cd}(\mathrm{OH})_{2}$ layer produced by the strong local alkalinization of the interface. This part of the cathodic reaction should furnish an electrode surface whose catalytic activity for the HER becomes extremely dependent on the cntire history of the electrode. This aspect of the reaction will be discussed in a future publication.

The overall reactions can be summarized in the reaction pattern depicted in Fig. 24. The proposed reaction model derived from a systematic change of a

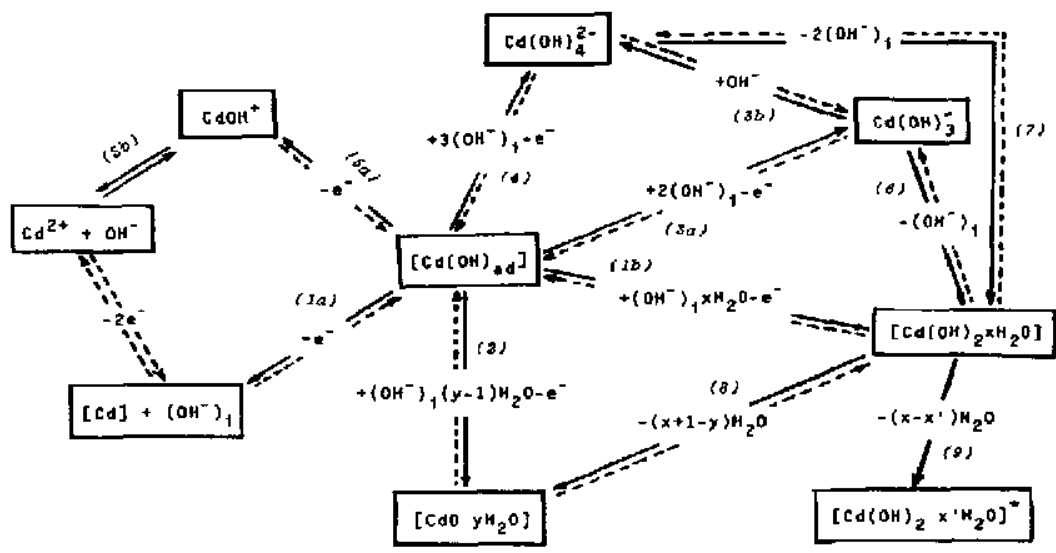

Fig. 24. Scheme of the probable structure of the metal/film/solution interphase, $x>x^{\prime}>y$. 


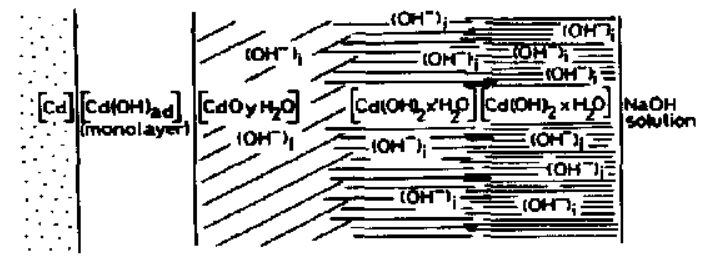

Fig. 25. Probable reaction pathways for the overall anodic and cathodic reactions, $x>x^{r}>y$.

large number of variables satisfy results earlier reported in the litcrature which mostly referred to a rather restricted range of experimental conditions.

From the study of the anodic and cathodic reactions one can conclude that the anodically formed layer acquires a composite structure of superposed layers as schematically scen in Fig. 25 . The relative thickness of the different layers should depend on the overall history of the cadmium electrode in the base solutions. Accordingly, the physicochemical propertics of the $\mathrm{Cd}(\mathrm{OH})_{2}$ species [55-57] and film thickness [58] affect both the electrodissolution and chemical dissolution rates of the surface layer.

Acknowledgement3--This work was financially supported by the Universidad Nacional de La Plata, the Consejo Nacional de Investigaciones Cientificas y Técnicas and the Comisión de Investigaciones Científicas de la Provincia de Buenos Aires.

\section{REFEKENCES}

1. P. C. Milner and V. B. Thomas, in Advances in Electrochemistry and Electrochemical Engineering (Edited by C. W. Tobias), Vol. 5, pp. 1-86. Interscience, New York (1967)

2. R. J. Lathan and N. A. Hampson, in Encyclopedia of the Electrachemistry of the Elements (Edited by $\Lambda$. J. Bard), Vol. I, pp. 155-233. Marcel Dekker, New York (1973).

3. R. D. Armstrong, K. Edmondson and G. D. West, in Specialist Periudicul Repurts on Electrochemistry, Vol. 4, pp. 18-32. The Chemical Society, London (1974).

4. S. Gross and R, J. Glockling, The Cadmium Electrode, A Review of the Status of Research. Final Report of Boeing Aerospace Company, Document D180-19046-2 (1976).

5. R. Barnard, J. appl. Electrochem. 11, 217 (1981).

6. S. U. Falk and A. J. Salkind, Alkaline Storage Battertes. Wiley, New York (1969).

7. General Electric, Nickel-Cadmium Battery, Application Enyineering Handbook. General Electric Co., Gainesville (1971).

8. P. Selanger, Ph.D. thesis, University of Lund, Sweden (1975).

9. F. von Sturm, in Comprehensive Treatise of Electrochemistry (Edited by J. O'M. Bockris, B. E. Conway, E. Ycager and R. E. White), Vol. 3, pp. 385-405. Plenum Press, New York (1981).

10. B. S. Hobbs, T. Keily and A. G. Palmer, J. appl. Electrochem. 8, 305 (1978); 9, 501 (1979); 10, 721 (1980).

11. K. Huber, J. electrochem. Soc. 100, 376 (1953); Z Elektrochem. 62, 675 (1958).

12. P. E, Lake and E. J. Casey, J. electrochem. Soc. 105, 52 (1958); 106, 913 (1959).

13. G. T. Croft, J. electrochem. Soc. 106, 278 (1959).
14. I. Sanghi, S. Visvanathan and S. Ananthanarayanan, Electrochim. Acta 3, 65 (1960).

15. R. Oshe, Z. Elekrrochem. 64, 1171 (1960).

16. M. W. Breiter and J. L. Weininger, J. electrochem. Soc. 113, 651 (1966).

17. R. D. Armstrong, E. H. Boult, D. F. Porter and H. R. Thirsk, Electrochim. Acta 12, 1245 (1967).

18. M. W. Breiter and W. Vedder, Trans. Faraday Soc. 63, 1042 (1967); Electrochim. Acta 13, 1405 (1968).

19. Ya. D. Zytner, E. A. Maksimyuk, V. A. Nikol'skii, N. I. Alekseeva and E. A. Berkman, Elektrokhimiya 7, 1581 (1971).

20. Yu. I, Obedkov and L. A. L'vova, Elektrokhimiyu 9, 1649 (1973); 10, 341 (1974); 11, 130 (1975).

21. K. D. Armstrong and $K$. Edmondson, J. electroanal. Chem. 53, 371 (1974).

22. B. N. Afanas'ev, V. I. Bukarinov and N. N. Milyutin, Elektrokhimiya 10, 134 (1974); 11, 270 (1975).

23. R. Barnard, K. Edmondson, J. A. Lee and F. L. Tye, $J$. appl. Electrochem. 6, 107 (1976).

24. M. W. Breiter, Electrochim. Acta 22, 219 (1977)

25. D. K. Grachev, Elektrokhimiya 14, 1830 (1978); 14, 1871 (1978).

26. J. A. Garrido Ponce, E. Perez Gonzalez and J. Virgili Vinade, An-Quim. (Ser. A) 78, 268 (1982); 78, 275 (1982); 79,656 (1983).

27. S. B. Saidman, M. Lopez Teijelo, J. R. Vilche and A. J. Arvia, An. 4th Simp. Bras. Eletroquim. Eletroanal., pp. 87-98 (1984).

28. M. Lopez Teijelo, J. R. Vilche and A. J. Arvia, $J$. electroanal. Chem. 131, 331 (1982); 162, 207 (1984).

29. Y. Okinaka, in Standard Potentials in Aqueous Solution (Edited by A. J. Bard, R. Parsons and J. Jordan), pp. 257-265. Marcel Dekker, New York (1985).

30. G. A. Parks, Chem. Rev. 65, 177 (1965).

31. J. R. Vilche and A. J. Arvia. Proc. 7th Intern. Congr. Met. Corros., Rio de Janeiro, pp. 245-266 (1978); Acto Cient. Venez. 31, 408 (1980); Anal. Acad. Cs. Ex. Fis. Nat., Buenos Aires 33, 33 (1981).

32. R. S. Schrebler Guzmán, J. R. Vilche and A. J. Arvia, Corros. Sci. 18, 765 (1978); Electrochim. Acta 24, 395 (1979); J. appl. Electrochem. 11, 551 (1981); Anal. Asoc. Quim. Arg. 70, 999 (1982).

33. H. Gomez Meier, J. R. Vilche and A. J. Arvia, J. electroanal. Chem. 134, 251 (1982).

34. M. E. Vela, J. R. Vilche and A. J. Arvia, J. appl. Electrochem. 16, 490 (1986).

35. D. M. Drazic and C. S. Hao, Glasnik Hem. drustea Beograd 47, 649 (1982).

36. G. T. Burstein and D. H. Davies, Corros. Sci. 20, 1143 (1980); J. electrochem. Soc. 128, 33 (1981)

37. G. T. Burstein and R. C. Newman, Electrochim. Acta 25 , 1009 (1980)

38. G. T. Burstein and G. W. Ashley, Corrosion 39, 241 (1983).

39. K. E. Heusler and L. Gaiser, J. electrochem. Soc. 117, 762 (1970).

40. M. W. Breiter and J. L. Weininger, J. electrochem. Soc. 113,651 (1966).

41. G. T. Burstein, $J$, electrochem. Soc. 130, 2133 (1983).

42. Y. Okinaka, J. electrochem. Soc. 117, 289 (1970).

43. R. D. A rmstrong and G. D. West, J. electroanal. Chem. 30, 385 (1971).

44. J. Leonardi, R. Bonnaterre, R. Doisneau and J. P. Stervinov GS News Tech. Report 37, 9 (1978).

45. F. G. Will and H. J. Hess, J. electromem. Soc. 120, 1 (1973).

46. E. J. Casey and C. L. Gardner, J. electrochem. Soc. 122 , 851 (1975).

47. M. W. Breiter, Electrochim. Acta 22, 1219 (1977).

48. J. O. Zerbino, J. R. Vilche and A. J. Arvia, J. appl. Electrochem. 11, 703 (1981).

49. R. S. Schrebler Guzmán, J. R. Vilche and A. J. Arvia, J. appl. Electrochem. 9, 183 (1979); 9, 321 (1979). 
50. H. Gomez Meier, J. R. Vilche and A. J. Arvia, J. appl. Electrochem. 10, $611(1980) ; J$. electroanal. Chem. 138, 367 (1982).

51. M. E. Folquer, J. R. Vilche and A. J. Arvia, J. electrochem. Soc. 127, 2634 (1980); J. electroanal. Chem. 172, 235 (1984).

52. V. A. Macagno, J. R. Vilche and A. J. Arvia, J. electrochem. Soc. 129, 301 (1982).

53. L. M. Gassa, J. R. Vilche and A. J. Arvia, J. appl. Electrochem. 13, 135 (1983)

54. J. F. Konig, A. Sehili, H. Hamdani and P. Chartier, J. appl.
Electrochem. 14, 241 (1984); 14, 247 (1984).

55. M. W. Breiter and W. Vedder, Electrochim. Acta 13, 1405 (1968).

56. L. A. L'vova, 1. A. Kazarinov, G. V. Suchkova and I. L. Ivanova, Elektrokhimiya 15, 1051 (1979).

57. I. A. Kazarinov, L. A. L'vova and I. L. Ivanova, Elektrokhimiya 16, 809 (1980).

58. M. I. da Silva Pereira and L. M. Peter, J. electroanal. Chem. 125, 401 (1981).

59. R. M. Smith and A. E. Martell, in Critical Stability Constants, Vol. 4, p. 9. Plenum Press, New York (1976). 